Çukurova Üniversitesi Mühendislik Mimarlık Fakültesi Dergisi, 31(1), 429-439 ss., Haziran 2016

Cukurova University Journal of the Faculty of Engineering and Architecture, 31(1), pp. 429-439, June 2016

\title{
Çekme Rijitleşmesinin FRP ve Çelik Donatılı Betonarme Kirişlerin Yük-Deplasman Davranışı Üzerindeki Etkisi
}

\author{
İsmail ÜNSAL ${ }^{1}$, Cengiz DÜNDAR ${ }^{1}$, A. Kamil TANRIKULU ${ }^{* 1}$ \\ ${ }^{1}$ Çukurova Üniversitesi, Mühendislik Mimarlık Fakültesi, Innşaat Mühendisliği Bölümü, Adana \\ Geliş tarihi: 10.02.2016 Kabul tarihi: 09.03.2016
}

\section{Özet}

Bu çalışmada çekme rijitleşmesinin, FRP ve çelik donatılı betonarme kirişlerin yük-deplasman davranışı üzerindeki etkisi teorik olarak incelenmiştir. Bu amaçla yapılan analizlerde, literatürde mevcut çeşitli deneysel çalışmalarda test edilmiş olan 12 adet FRP ve çelik donatılı kiriş numunesi esas alınmıştır. Çekme rijitleşmesinin eğilme davranışı üzerindeki etkisini incelemek üzere hesaplarda iki bölgeli doğrusal çekme rijitleşmesi modeli kullanılmıştır. Bu modelde çekme rijitleşmesini $\alpha_{t s}$ parametresi kontrol etmektedir. Yapılan analizlerle, her bir kiriş için $\alpha_{t s}$ parametresinin 2 ile 25 arasında değişen değerlerine bağlı olarak yük-deplasman eğrisi elde edilmiştir. Analizlerden elde edilen sonuçlar, mevcut deneysel çalışmalarda verilen kiriş numunelerine ait yük-deplasman ilişkileriyle karşılaştırılmıştır. Deney sonuçları ile en uyumlu yük-deplasman ilişkisini sağlayan $\alpha_{t s}$ değerleri kaydedilmiştir. Sonuç olarak yükdeplasman davranışı belirlenmek istenen FRP ve çelik donatılı betonarme kirişlerin analizi için hesaplarda esas alınması gereken $\alpha_{t s}$ değerinin, donatı oranı ve donatı elastisite modülü gibi faktörlere bağlı olarak önemli oranda değişkenlik gösterdiği belirlenmiştir.

Anahtar Kelimeler: Çekme rijitleşmesi, FRP donatılı kiriş, Şekil değişme, Deplasman

\section{Tension Stiffening Effect on Load-Deflection Behavior of Concrete Beams Reinforced with FRP and Steel Bars}

\begin{abstract}
In this study, tension stiffening effect on load-deflection behavior of concrete beams reinforced with FRP and steel bars is investigated. A total of 12 FRP reinforced concrete beam specimens, available in the literature, were considered in the analysis. In order to investigate tension stiffening effect on flexural behavior, bilinear tensile stress-strain model was considered for concrete material. In this model the parameter $\alpha_{t s}$ controls the tension stiffening effect on the load-deflection behavior of the beam. Loaddeflection curves for the specimens were obtained with varying $\alpha_{t s}$ between 2 to 25 , and then were compared with the experimental results. In conclusion it is observed that the value of $\alpha_{t s}$ to be taken into account for calculations in order to predict load-deflection behavior of reinforced concrete beams significantly depend on the reinforcement ratio and the mechanical properties of reinforcement.
\end{abstract}

Keywords: Tension stiffening, FRP reinforced beam, Strain, Load-deflection, Moment-curvature $\begin{aligned} \text { Yazışmaların yapılacağı yazar: } & \text { A. Kamil TANRIKULU, Cukurova Ü. Mühendislik Mimarlık } \\ & \text { Fakültesi, Inşaat Mühendisliği Bölümü, Adana. akt@cu.edu.tr }\end{aligned}$ 


\section{GíRiş}

Eğilmeye çalışan betonarme elemanlarda, ilk çatlamadan hemen sonra komşu iki çatlak arasında kalan beton, donatı ile olan aderansı nedeniyle oluşan çekme gerilmesinin taşınmasına katkı sağlamaktadır. Betonarme elemanın bu andaki eğilme rijitliği, beton çekme dayanımı ihmal edilerek hesaplanan eğilme rijitliğinden daha büyük olmaktadır. Çekme rijitleşmesi denilen bu etki, özellikle düşük donatı oranına sahip kiriş kesitlerinde çatlamanın ilk aşamalarında moment eğrilik ilişkisine yön vermekte ve yük altında eğilme davranışını önemli ölçüde etkilemektedir.

Çekme rijitleşmesinin gerek FRP donatılı gerekse çelik donatılı betonarme kirişler üzerindeki etkisinin belirlenmesine ilişkin pek çok sayıda teorik ve deneysel çalışmalar yapılmıştır. Stramandinoli ve Rovere [1] çalışmalarında çekme rijitleşmesi için, çelik ve betonun modüler oranına ve donatı oranına bağlı olan, CEB modelinden türetilmiş bir parametrenin belirleyici olduğu yeni bir model önermişlerdir. Allam, Shoukry, Rashad, Hassan [2] önerdikleri analitik modelde çekme rijitleşmesinin alt sınırını belirlemeye çalışmışlardır. Ayrıca çekme bölgesindeki betonun toplam katkısını hesaplamak üzere yapılan sonlu elemanlar analizi ile elde ettikleri değeri elemanda çekme rijitleşmesinin üst sınırı olarak kabul etmişlerdir. Yaptıkları analizlerde artan eğilme donatısı oranına karşılık çekme rijitleşmesinin azaldığını gözlemlemişlerdir. Wu ve Gilbert [3], modifiye ettikleri CEB-FIB modelini nonlineer sonlu elemanlar programına uyarlamışlar ve çekme rijitleşmesini kullanılabilirlik sınır durumunda belirlemeye çalışmışlardır. Önerdikleri model ile eksenel çekme yükü altındaki elemanlara ait gerilme, deformasyon ve çatlak genişlikleri belirlenmiştir. Yankelevsky, Jabareen ve Abutbul [4], eksenel çekme ile yüklenen silindir kesitli, tek donatılı bir elemanın artan yük altında rijitliğindeki sürekli değişimi inceleyerek bir boyutlu model geliştirmiş̧lerdir.

Literatürde mevcut olan iki bölgeli doğrusal çekme rijitleşmesi modelinde çekme rijitleşmesini $\alpha_{t s}$ parametresi kontrol etmekte ve $\alpha_{t s}$ için 2 ile 25 arasında bir değer alınması önerilmektedir. Ancak bu değer aralığındaki farklı $\alpha_{t s}$ değerleri esas alınarak yapılan hesaplardan oldukça farklı yükdeplasman eğrileri elde edilmektedir.

$\mathrm{Bu}$ çalışmada, $\alpha_{t s}$ parametresi donatı oranı ve donatının mekanik özellikleri gibi etkenlerle ilişkilendirilmiştir. $\mathrm{Bu}$ amaçla yapılan analizler için, literatürde mevcut olan çeşitli deneysel çalışmalarda test edilmiş 12 adet FRP donatılı kiriş numunesi esas alınmıştır. Her bir kiriş için $\alpha_{t s}$ parametresinin 2 ile 25 arasında değişen değerlerine bağlı olarak yapılan analizlerle yükdeplasman eğrileri elde edilmiştir. Analiz sonuçları, mevcut deneysel çalışmalarda verilen kiriş numunelerine ait yük-deplasman ilişkileriyle karşılaştırılmıştır. Deney sonuçları ile en uyumlu yük-deplasman ilişkisini belirleyen $\alpha_{t s}$ değerleri kaydedilmiştir. Yük-deplasman davranışı belirlenmek istenen FRP ve çelik donatılı betonarme kirişlerin analizi için hesaplarda esas alınması gereken $\alpha_{t s}$ değerinin, donatı elastisite modülü ve donatı oranı gibi faktörlere bağlı olarak önemli oranda değişkenlik gösterdiği belirlenmiştir.

\section{MALZEME MODELLERİ VE SAYISAL YÖNTEM}

Bu çalışmada, Dündar ve arkadaşları [5] tarafindan geliştirilmiş olan, FRP ve çelik donatılı yatay taşıyıcı sistemleri herhangi bir yükleme ve mesnetlenme koşulu altında analiz ederek elemanların yük-deplasman davranışını belirleyen bir bilgisayar programı kullanılmıştır. Sistem deplasmanlarının hesabında rijitlik matrisi yöntemi kullanılmaktadır. Programda kullanılan sayısal yöntemde, analizin ilk adımında sistemdeki farklı donatıya sahip tüm kesitler için moment - eğrilik ilişkileri kesitin taşıma gücü moment kapasitesi seviyesine kadar hesaplanmakta ve saklanmaktadır. Moment-eğrilik ilişkileri hesaplanırken ilk olarak tarafsız eksen derinliği ve beton basınç bölgesinde en dış lifteki şekil değiştirme $\left(\varepsilon_{c}\right)$ için bir başlangıç değeri belirlenmekte, denge denklemleri ve uygunluk şartı sağlanıncaya kadar iterasyonlara devam edilmektedir. Her $\left(\varepsilon_{c}\right)$ değeri için yeni bir momenteğrilik değeri hesaplanmaktadır. Beton basınç 
bölgesinde en dış lifte maksimum şekil değiştirmeye ulaşılıncaya kadar moment-eğrilik ilişkileri hesaplanmaya devam edilmektedir. Daha sonra dış yükler altında sistemin lineer elastik analizi yapılmaktadır. Bu analiz sonucu elde edilen eleman uç kuvvetleri kullanılarak elemanlarda çatlamış ve çatlamamış bölgeler belirlenmekte ve her bölgenin eleman rijitliğine katkısı daha önce belirenmiş olan moment-eğrilik ilişkileri de kullanılarak sayısal integrasyon tekniği ile hesaplanmaktadir.

Programda elemanlara ait efektif rijitlikler, çatlamış kesit analizi ile hesaplanan moment eğrilik ilişkisinden elde edilebildiği gibi, literatürdeki ACI440.1R [6], ACI440-H [7], CEB [8], Bischoff [9], ISIS [10] gibi mevcut modeller de dikkate alınarak hesaplanabilmektedir. Bu şekilde eleman rijitlikleri belirlendikten sonra sistem rijitlik matrisi oluşturularak çözüme gidilmekte, dügüum deplasmanları ve eleman uç kuvvetleri hesaplanmaktadır.

Programa tanıtılan yakınsama kriteri sağlanıncaya kadar iterasyonlara devam edilmektedir. Program dikdörtgen kesitli yatay taşıyıcı sistemleri üniform veya tekil yükler altında çözümleyebilmekte, kesitlerde bulunan çelik veya FRP donatısını bulundukları konuma göre çekme veya basınç donatısı olarak dikkate alabilmektedir. Beton basınç bölgesi için gerilme-şekil değiştirme modeli olarak Hognestad veya CEB-FIB [11] modelleri seçilebilmektedir. Beton çekme bölgesi için literatürde verilen herhangi bir gerilme-şekil değiştirme modeli kullanılabilmektedir.

$\mathrm{Bu}$ çalışmada beton basınç bölgesinde gerilmeşekil değiştirme ilişskisi için Şekil 1 de verilen ve (1) denklemlerinde tanımlanan CEB-FIB modeli kullanılmıştır. Denklemlerde $\varepsilon_{c o}=0,002$, $\varepsilon_{c u}=0.003$ alınmıştır.

$$
\begin{aligned}
& f_{c}=f_{c}^{\prime}\left[\frac{2 \varepsilon_{c}}{\varepsilon_{c o}}-\left(\frac{\varepsilon_{c}}{\varepsilon_{c o}}\right)^{2}\right] \quad \varepsilon_{c} \leq \varepsilon_{c o} \\
& f_{c}=f_{c}^{\prime} \quad \varepsilon_{c o} \leq \varepsilon_{c} \leq \varepsilon_{c u}
\end{aligned}
$$

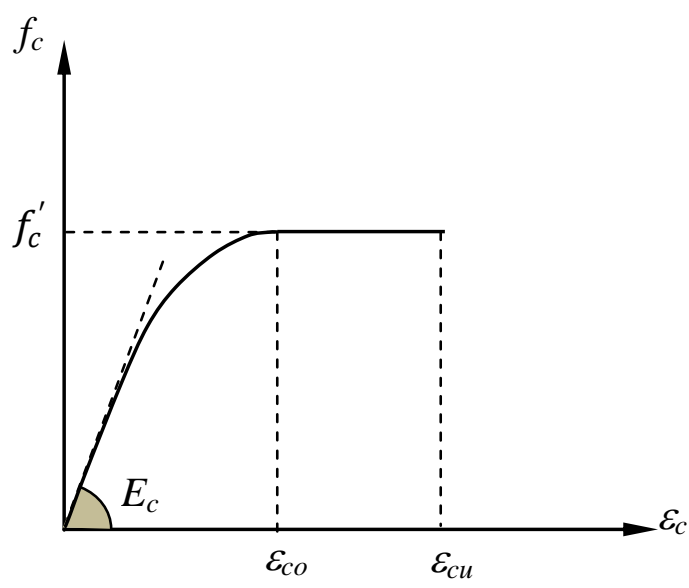

Şekil 1. Beton basınç bölgesinde gerilme-şekil değiştirme için CEB-FIB modeli

FRP gerilme-şekil değiştirme ilişkisi Şekil 2 de de görüldüğü gibi kopma anına kadar lineer elastik alınmış ve (2) denklemi ile tanımlanmıştır.

$$
f_{f}=E_{f} \varepsilon_{f} \quad \varepsilon_{f} \leq \varepsilon_{f u}
$$

(2) denkleminde $f_{f}$ ve $\varepsilon_{f}$ sirasiyla FRP donatısındaki gerilme ve şekil değiştirmeyi; $E_{f}$ FRP donatısının elastisite modülünü ve $\varepsilon_{f u}$ kopma anındaki şekil değiştirmesini göstermektedir.

Çeliğin gerilme-şekil değiştirme ilişkisi için, Şekil 3 te verilen ve (3) denklemi ile tanımlanan elastoplastik malzeme modeli kullanılmıştır.

$f_{s}=E_{s} \varepsilon_{s} \leq f_{y}$

(3) denkleminde $f_{s}$ and $\varepsilon_{s}$ sırasıyla çeliğin gerilme ve şekil değiştirmesini, $E_{s}$ ve $f_{y}$ ise çeliğin elastisite modülü ve akma gerilmesini göstermektedir.

\section{3. ÇEKME RİJITLEŞMESI PARAMETRESININN KIRIŞLERIN EĞILLME DAVRANIŞINA ETKİSi}

Kirişlerde çekme rijitleşmesi etkisi, eğilme davranışı altında elemanda ilk çatlamadan hemen sonra komşu iki çatlak arasında kalan betonun, 


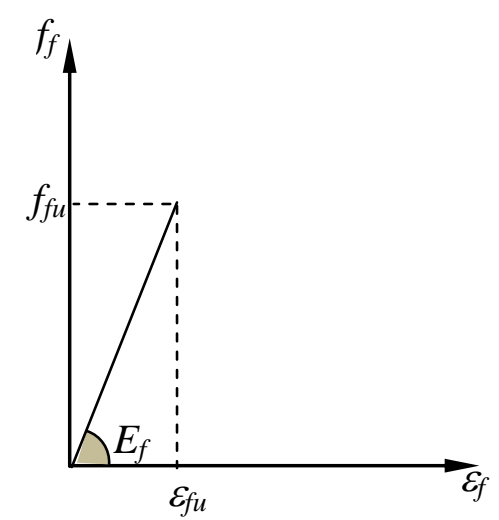

Şekil 2. FRP donatısının gerilme-şekil değiştirme ilişkisi

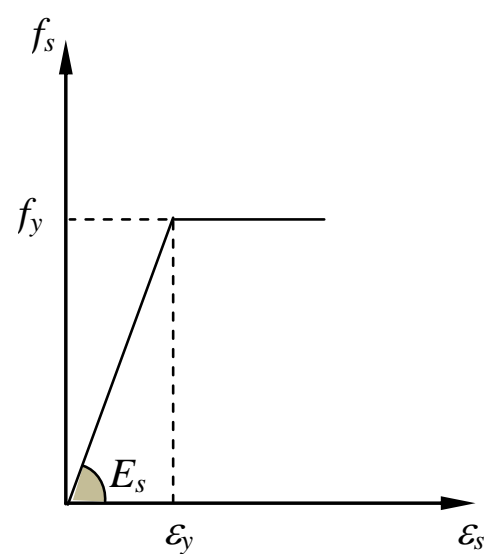

Şekil 3. Çeliğin gerilme-şekil değiştirme ilişkisi

donatı ile olan aderansı nedeniyle çekme bölgesindeki mevcut gerilmenin taşınmasına katkı sağlaması olarak tanımlanmaktadır. Aynı zamanda elemanın eğilme rijitliğine de sağladığı katkı nedeniyle bu etki, özellikle düşük donatı oranına sahip kiriş kesitlerinde çatlamanın ilk aşamalarında moment - eğrilik ilişkisine yön vermekte ve yük altında eğilme davranışını önemli ölçüde etkilemektedir. Bu çalışmada, çekme rijitleşmesi etkisini incelemek üzere iki bölgeli doğrusal çekme rijitleşmesi modeli esas alınmıştır. Şekil 4 te ve (4) denklemlerinde görüldüğü üzere iki bölgeli doğrusal çekme rijitleşmesi modelinde çekme rijitleşmesini $\alpha_{t s}$ parametresi kontrol etmektedir. $\varepsilon_{c t u}$ kırılma anındaki şekil değiştirme olup $\left(\varepsilon_{c r}\right)$ çatlama anındaki şekil değiştirme değerinin $\alpha_{t s}$ parametresi ile çarpılması sonucu elde edilmektedir.

$$
\begin{aligned}
& f_{t}=E_{c} \varepsilon_{t} \quad \varepsilon_{t} \leq \varepsilon_{c r} \\
& f_{t}=f_{r}-\frac{f_{r}}{\varepsilon_{c t u}-\varepsilon_{c r}}\left(\varepsilon_{t}-\varepsilon_{c r}\right), \\
& \varepsilon_{c t u} \geq \varepsilon_{t} \geq \varepsilon_{c r} \\
& \varepsilon_{c t u}=\alpha_{t s} \varepsilon_{c r}
\end{aligned}
$$

(4) denklemlerinde $f_{t}$ betonun çekme gerilmesini, $E_{c}$ betonun elastisite modülünü, $f_{r}$ ise betonun çatlama gerilmesini göstermektedir.

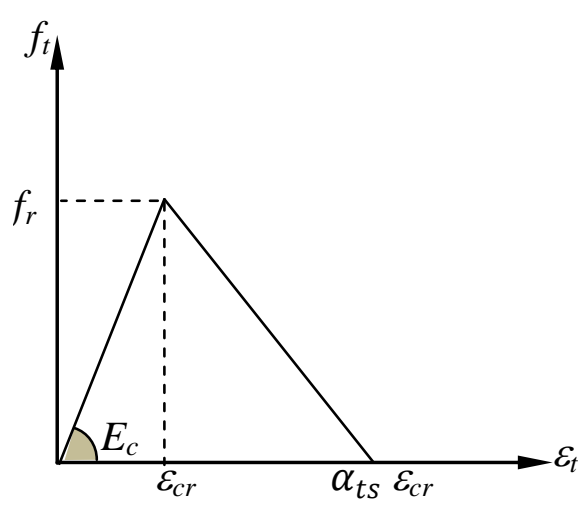

Şekil 4. İki bölgeli doğrusal çekme rijitleşmesi modeli

Literatürde çekme rijitleşmesi parametresi $\alpha_{t s}$ için 2 ile 25 arasında değer alınması önerilmektedir. Ancak bu değer aralığındaki farklı $\alpha_{t s}$ değerleri esas alınarak yapılan hesaplardan oldukça farklı yük-deplasman eğrileri elde edilmektedir. $\mathrm{Bu}$ çalışmada, $\alpha_{t s}$ parametresinin kirişlerin eğilme davranış1 üzerindeki etkisi incelenmiştir. $\mathrm{Bu}$ amaçla yapılan analizler için, literatürde mevcut olan çeşitli deneysel çalışmalarda test edilmiş 12 adet FRP ve çelik donatılı kiriş numunesi esas alınmıştır. Her bir kiriş için $\alpha_{t s}$ parametresinin 2 ile 25 arasında değişen değerlerine bağlı olarak yapılan analizlerle yük-deplasman eğrileri elde edilmiştir. Analiz sonuçları, mevcut deneysel çalışmalarda verilen kiriş numunelerine ait yükdeplasman ilişkileriyle karşılaştırılmıştır. Deney sonuçları ile en uyumlu yük-deplasman ilişkisini belirleyen $\alpha_{t s}$ değerleri kaydedilmiştir. Yük- 
deplasman davranışı belirlenmek istenen FRP ve çelik donatılı betonarme kirişlerin analizi için hesaplarda esas alınması gereken $\alpha_{t s}$ değerinin, donatı elastisite modülü ve donatı oranı gibi faktörlere bağlı olarak önemli oranda değişkenlik gösterdiği belirlenmiştir. İncelenen 12 adet FRP ve çelik donatılı kiriş numunesinin ait olduğu çalışmalar aşağıda verilmektedir:

(a) Bir adet çelik, üç adet karbon lifli polimer (CFRP) donatılı sürekli kiriş ile iki adet karbon lifli polimer donatılı basit mesnetli kiriş (Mahroug, Ashour, Lam) [12] deneyi. Bu çalışmada test edilmiş olan kirişlerin yüksekliği $150 \mathrm{~mm}$ ve genişliği $500 \mathrm{~mm}$ olup basit mesnetli ve sürekli kirişlerin açıklıkları 2000 mm'dir.

(b) Bir adet çelik, üç adet bazalt lifli polimer (BFRP) donatılı sürekli kiriş ile iki adet bazalt lifli polimer donatılı basit mesnetli kiriş (Mahroug, Ashour, Lam) [13] deneyi. Bu çalışmada test edilmiş olan kirişlerin yüksekliği $150 \mathrm{~mm}$ ve genişliği $500 \mathrm{~mm}$ olup basit mesnetli ve sürekli kirişlerin açıklıkları 2000 mm’dir.

Deney sürekli kirişlerinin mesnetlenme ve yükleme durumu Şekil 5' te görülmektedir.

Kiriş numunelerine ait beton silindir basınç dayanımları 25 ile $43 \mathrm{MPa}$ arasında değişmektedir. Kirişlerin açıklık ortasında ve mesnet bölgesindeki kesitlerine (A-A ve B-B kesitleri) ait donatı detayları ve mekanik özellikleri, Çizelge 1' de verilmektedir.

\section{ARAŞTIRMA BULGULARI VE TARTIŞMA}

Yapılan analizler sonucunda 12 adet FRP ve çelik donatılı her bir sürekli kirişe ait yük-deplasman eğrisi, $\alpha_{t s}$ parametresinin 2 ile 25 arasında değişen değerleri için elde edilmiştir. Analiz sonuçları, Şekil 7(a-1) deki grafiklerde, mevcut deneysel çalışmalarda verilmiş olan kiriş numunelerine ait yük-deplasman ilişkileriyle karşılaştırılmaktadır.

Şekil 7(a) ve 7(b) grafikleri incelendiğinde, denge altı donatı oranına sahip olan iki kiriş için deney

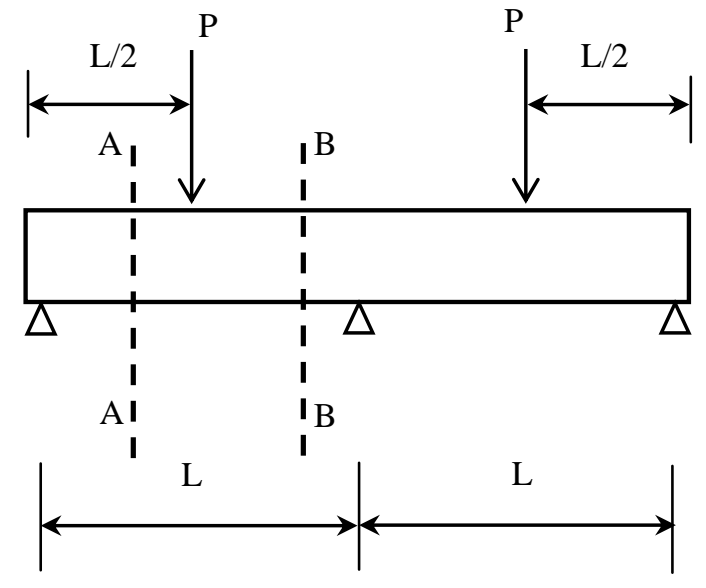

Şekil 5. Sürekli kiriş ve yükleme durumu

sonuçlarına en yakın davranışı sağlayan $\alpha_{t s}$ değerlerinin önemli ölçüde farklı olduğu görülmektedir. Bazalt lifli polimer donatılı kiriş (CBUU) için $\alpha_{t s}$ değeri 25 olarak bulunurken, karbon lifli polimer donatılı kiriş (CCUU) için $\alpha_{t s}$ değeri 12 olarak elde edilmiştir. Çizelge 1 'de görüleceği üzere bu kirişlerin açıklıkta çekme donatısı oranı aynı olup \%0,24 iken beton basınç dayanımları sırasıyla 42 ve $43 \mathrm{MPa}$ dir. $\rho_{f} / \rho_{f b}$ oranları ise CBUU kirişi için 0,83 ve CCUU kirişi için 0,67 dir. Kopma gerilmeleri bazalt ve karbon lifli polimer için sırasıyla $1250 \mathrm{MPa}$ ve $1773 \mathrm{MPa}$ dır. Aynı kesit ölçülerine sahip olan iki kiriş arasındaki en belirgin fark donatıların elastisite modülü olup CBUU kirişi için $50 \mathrm{GPa}$ ve CCUU kirişi için $137 \mathrm{GPa}$ dır. Burada $\alpha_{t s}$ parametresinin, donatı elastisite modülü $\left(E_{f}\right)$ ile önemli ölçüde ilişkili olduğu anlaşılmaktadır. Yüksek elastisite modülüne sahip FRP donatıların kullanıldığı kirişlerde $\alpha_{t s}$ parametresi için düşük değerler elde edilmektedir.

Şekil 7(c) ve 7(d) grafikleri karşılaştırıldığında, her ikisi denge üstü donatı oranına sahip olan CBOO ve CCOO kirişleri için deney sonuçlarına en yakın davranışı sağlayan çekme rijitleşmesi parametresi $\alpha_{t s}$ sırasıyla 16 ve 5 olarak elde edilmiştir. Çizelge 1'de görüleceği üzere bu kirişlerin açıklıkta çekme donatı yüzdeleri sırasıyla $\% 0,63$ ve $\% 0,90$ olup $\quad \rho_{f} / \rho_{f b}$ oranları ise 2,52 ve 1,58 dir. 
Çizelge 1. Kirişlere ait donatı detayları ve mekanik özellikleri

\begin{tabular}{|c|c|c|c|c|c|c|c|c|c|c|c|c|c|}
\hline \multirow[b]{2}{*}{ Numune } & \multirow[b]{2}{*}{$\begin{array}{l}\vec{E} \\
2 \\
\bar{E} \\
\tilde{0} \\
0\end{array}$} & \multicolumn{5}{|c|}{ Section A-A } & \multicolumn{5}{|c|}{ Section B-B } & \multirow[b]{2}{*}{ ஸ̃ } & \multirow[b]{2}{*}{$\begin{array}{l}0 \\
0 \\
0\end{array}$} \\
\hline & & $\begin{array}{l}\text { 氚 } \\
\text { ڤั }\end{array}$ & $\begin{array}{l}\overrightarrow{\tilde{n}} \\
\tilde{U} \\
\bar{\Xi} \\
\tilde{\Xi} \\
\stackrel{0}{0}\end{array}$ & $\begin{array}{c}\rho_{f} \\
\%\end{array}$ & $\begin{array}{c}\rho_{f b} \\
\%\end{array}$ & 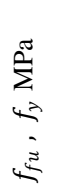 & $\begin{array}{l}\text { E्ञ } \\
\text { ڤั }\end{array}$ & $\begin{array}{l}\overline{\tilde{n}} \\
\tilde{U} \\
\tilde{\Xi} \\
\tilde{0} \\
\stackrel{0}{0}\end{array}$ & $\begin{array}{c}\rho_{f} \\
\%\end{array}$ & $\begin{array}{c}\rho_{f b} \\
\%\end{array}$ & 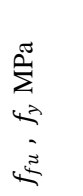 & & \\
\hline \multirow{2}{*}{$\mathrm{CCOU}^{12}$} & Alt & $5 \varnothing 12$ & CFRP & 0,9 & 0,57 & 1375 & $5 \varnothing 12$ & CFRP & - & - & 1375 & \multirow{2}{*}{137} & \multirow{2}{*}{37,8} \\
\hline & Üst & - & - & - & - & - & $3 \emptyset 8$ & CFRP & 0,24 & 0,36 & 1773 & & \\
\hline \multirow{2}{*}{$\mathrm{CCUU}^{12}$} & Alt & $3 \emptyset 8$ & CFRP & 0,24 & 0,36 & 1773 & $3 \emptyset 8$ & CFRP & - & - & 1773 & \multirow{2}{*}{137} & \multirow{2}{*}{42} \\
\hline & Üst & - & - & - & - & - & $3 \emptyset 8$ & CFRP & 0,24 & 0,36 & 1773 & & \\
\hline \multirow{2}{*}{$\mathrm{CCOO}^{12}$} & Alt & $5 \emptyset 12$ & CFRP & 0,9 & 0,57 & 1375 & $5 \emptyset 12$ & CFRP & - & - & 1375 & \multirow{2}{*}{137} & \multirow{2}{*}{40,2} \\
\hline & Üst & - & - & - & - & - & $5 \emptyset 8$ & CFRP & 0,9 & 0,57 & 1773 & & \\
\hline \multirow{2}{*}{$\mathrm{CS}_{2} \mathrm{UU}^{12}$} & Alt & $6 \varnothing 10$ & Steel & 0,75 & 2,88 & 575 & $6 \varnothing 10$ & Steel & - & - & 575 & \multirow{2}{*}{200} & \multirow{2}{*}{40,6} \\
\hline & Üst & - & - & - & - & - & $6 \varnothing 10$ & Steel & 0,75 & 2,88 & 575 & & \\
\hline \multirow{2}{*}{$\mathrm{CBOU}^{13}$} & Alt & $5 \varnothing 10$ & BFRP & 0,63 & 0,25 & 1350 & $5 \varnothing 10$ & BFRP & - & - & 1350 & \multirow{2}{*}{50} & \multirow{2}{*}{43} \\
\hline & Üst & - & - & - & - & - & $3 \emptyset 8$ & BFRP & 0,24 & 0,29 & 1250 & & \\
\hline \multirow{2}{*}{ CBUU $^{13}$} & Alt & $3 \varnothing 8$ & BFRP & 0,24 & 0,29 & 1250 & $3 \emptyset 8$ & BFRP & - & - & 1250 & \multirow{2}{*}{50} & \multirow{2}{*}{43} \\
\hline & Üst & - & - & - & - & - & $3 \emptyset 8$ & BFRP & 0,24 & 0,29 & 1250 & & \\
\hline \multirow{2}{*}{$\mathrm{CBOO}^{13}$} & Alt & $5 \emptyset 10$ & BFRP & 0,63 & 0,25 & 1350 & $5 \emptyset 10$ & BFRP & - & - & 1350 & \multirow{2}{*}{50} & \multirow{2}{*}{42} \\
\hline & Üst & - & - & - & - & - & $5 \emptyset 10$ & BFRP & 0,63 & 0,25 & 1350 & & \\
\hline \multirow{2}{*}{ CSUU $^{13}$} & Alt & $4 \varnothing 10$ & Steel & 0,50 & 2,27 & 575 & $4 \varnothing 10$ & Steel & - & - & 575 & \multirow{2}{*}{200} & \multirow{2}{*}{43} \\
\hline & Üst & - & - & - & - & - & $4 \varnothing 10$ & Steel & 0,50 & 2,27 & 575 & & \\
\hline $\mathrm{SCO}^{12}$ & Alt & $5 \varnothing 12$ & CFRP & 0,90 & 0,57 & 1375 & - & - & - & - & - & 137 & 43 \\
\hline $\mathrm{SCU}^{12}$ & Alt & $3 \emptyset 8$ & CFRP & 0,24 & 0,40 & 1773 & - & - & - & - & - & 137 & 43,4 \\
\hline $\mathrm{SBO}^{13}$ & Alt & $5 \emptyset 10$ & BFRP & 0,63 & 0,25 & 1350 & - & - & - & - & - & 50 & 44 \\
\hline $\mathrm{SBU}^{13}$ & Alt & $3 \emptyset 8$ & BFRP & 0,24 & 0,29 & 1250 & - & - & - & - & - & 50 & 41 \\
\hline
\end{tabular}




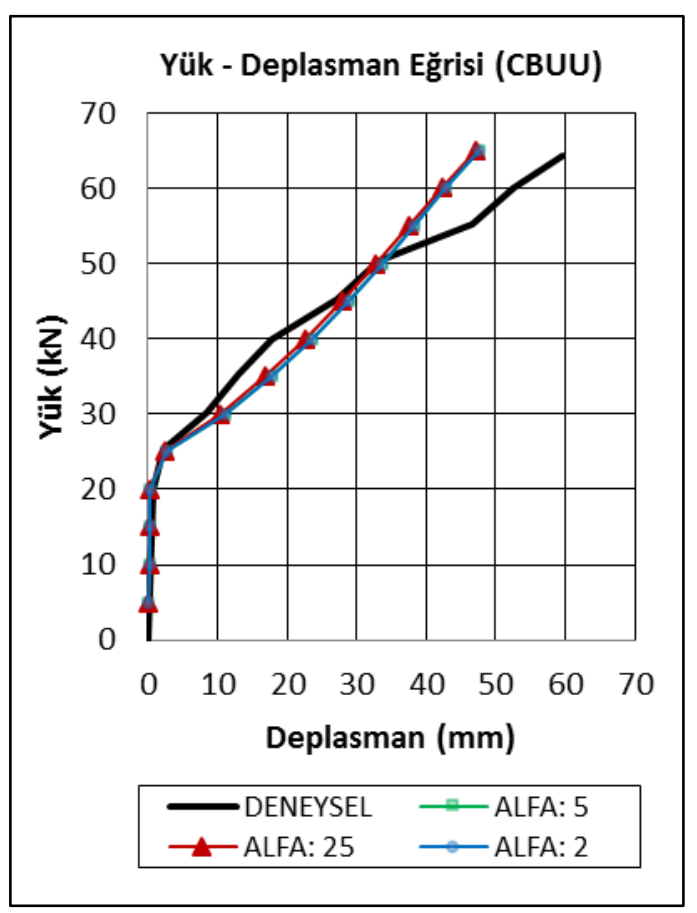

(a)

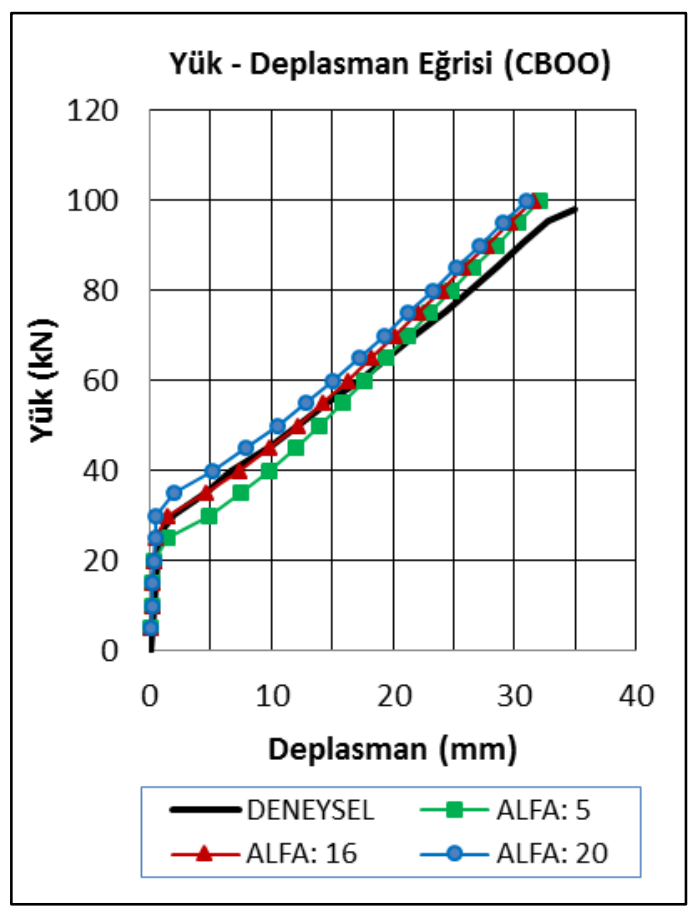

(c)

Şekil 7. Kirişlere ait yük-deplasman grafikleri

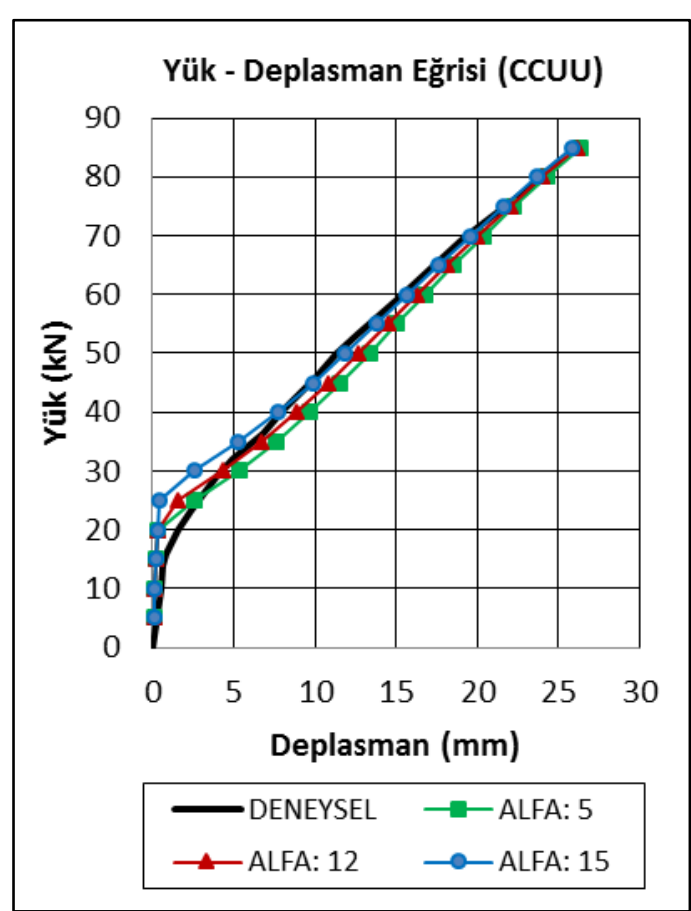

(b)

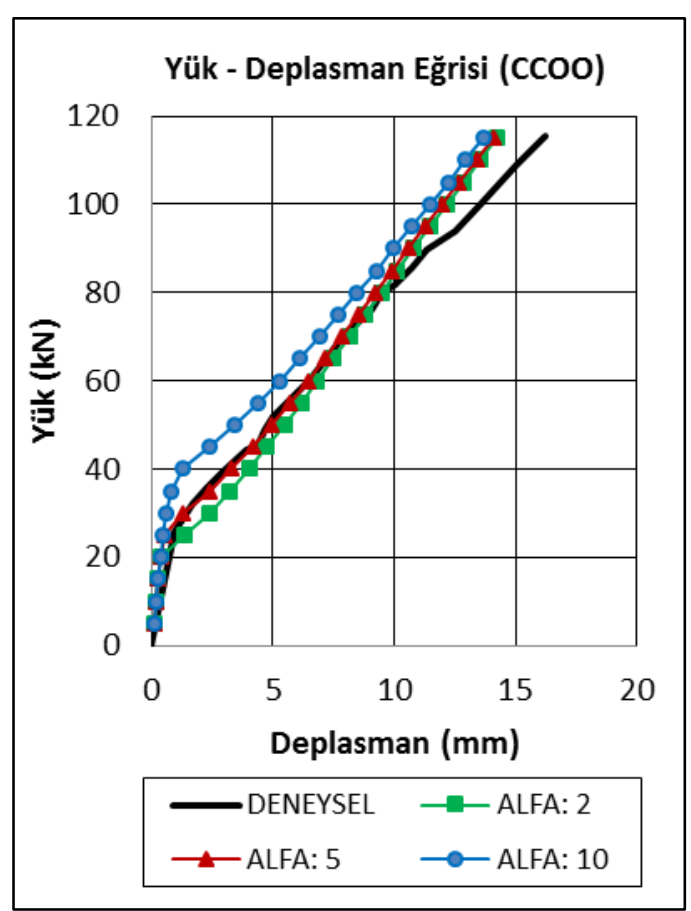

(d) 


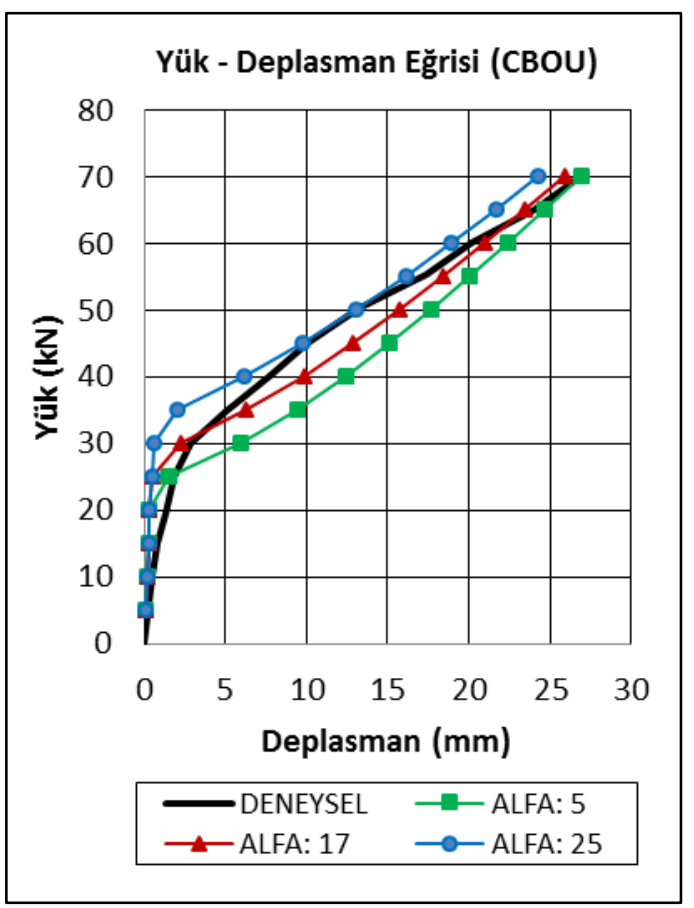

(e)

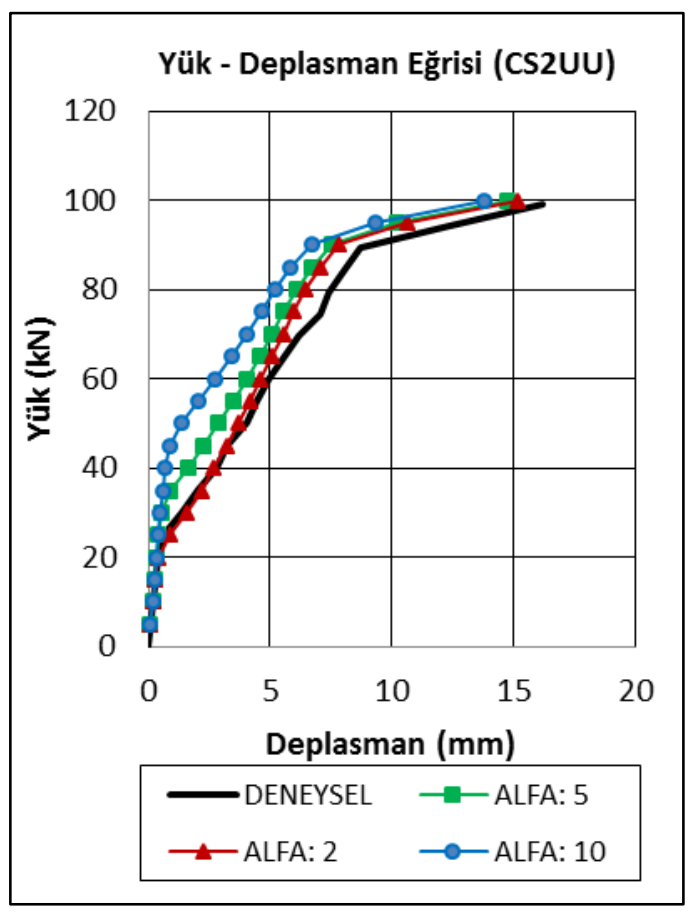

(g)

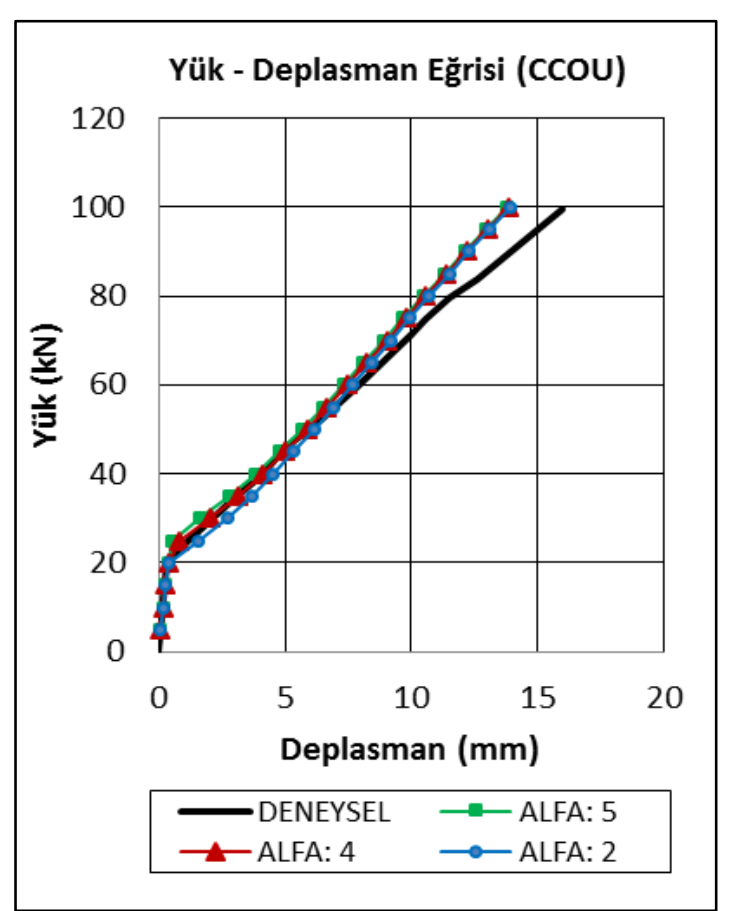

(f)

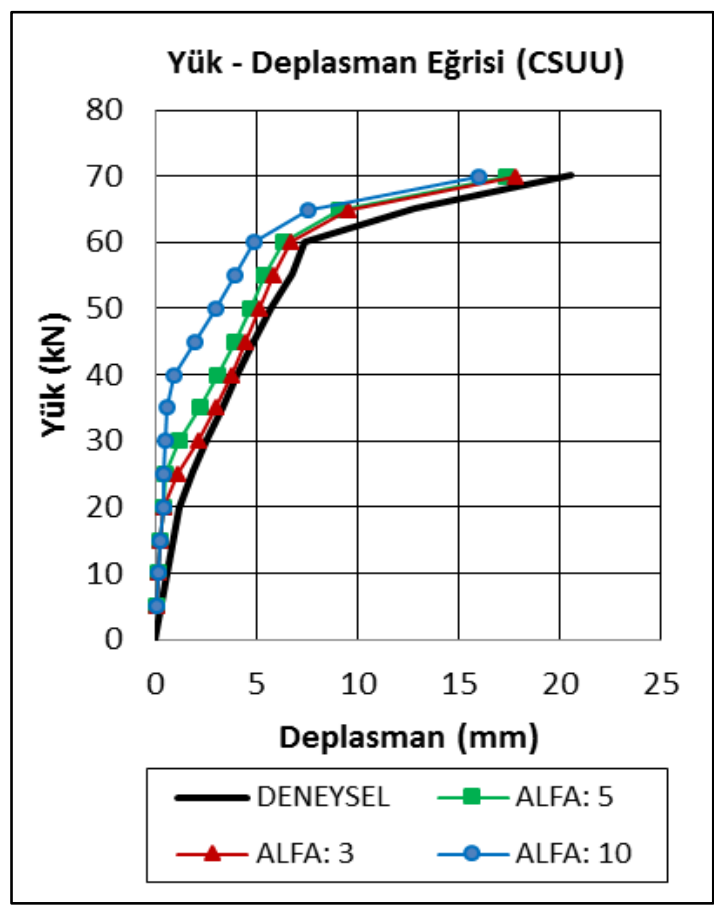

(h)

Ç.Ü.Müh.Mim.Fak.Dergisi, 31(1), Haziran 2016 


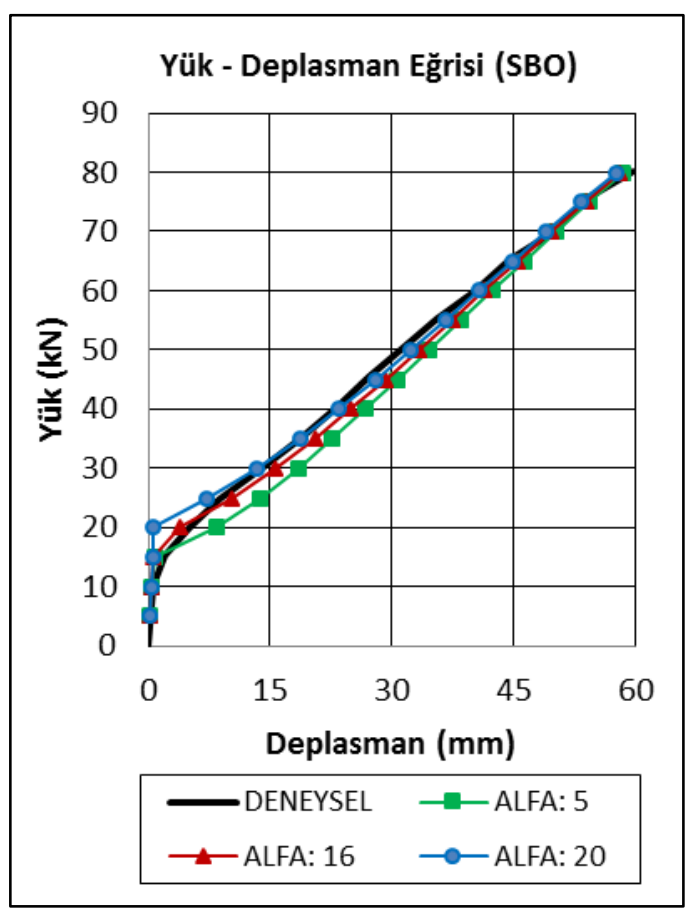

(i)

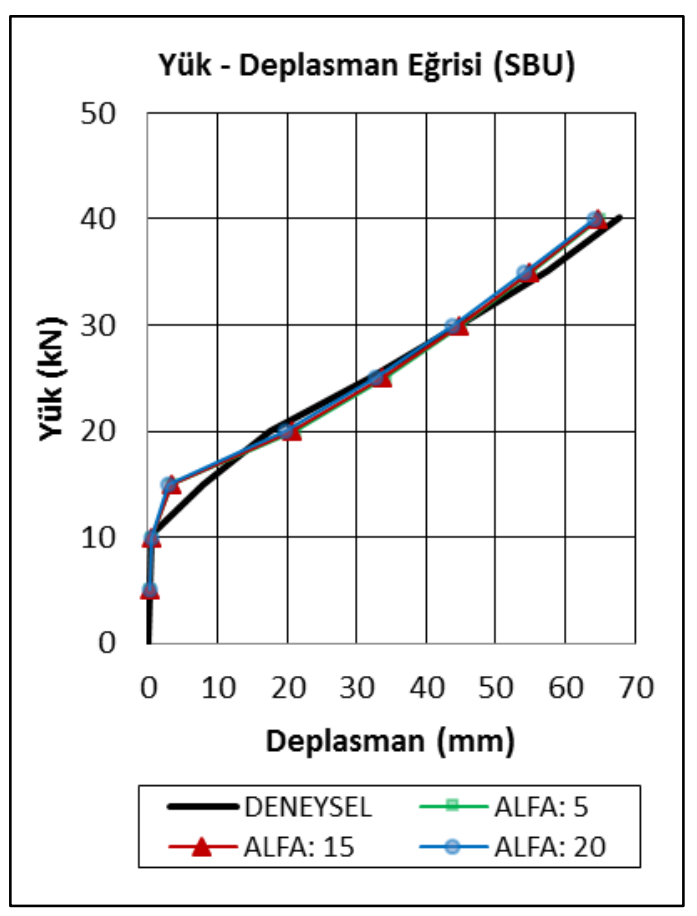

(k)

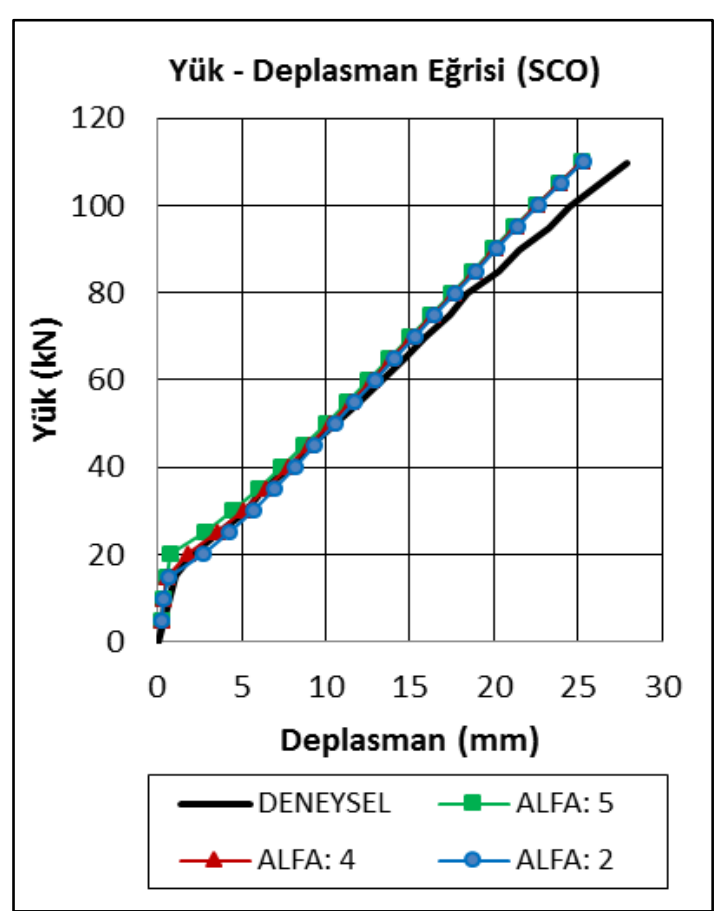

(j)

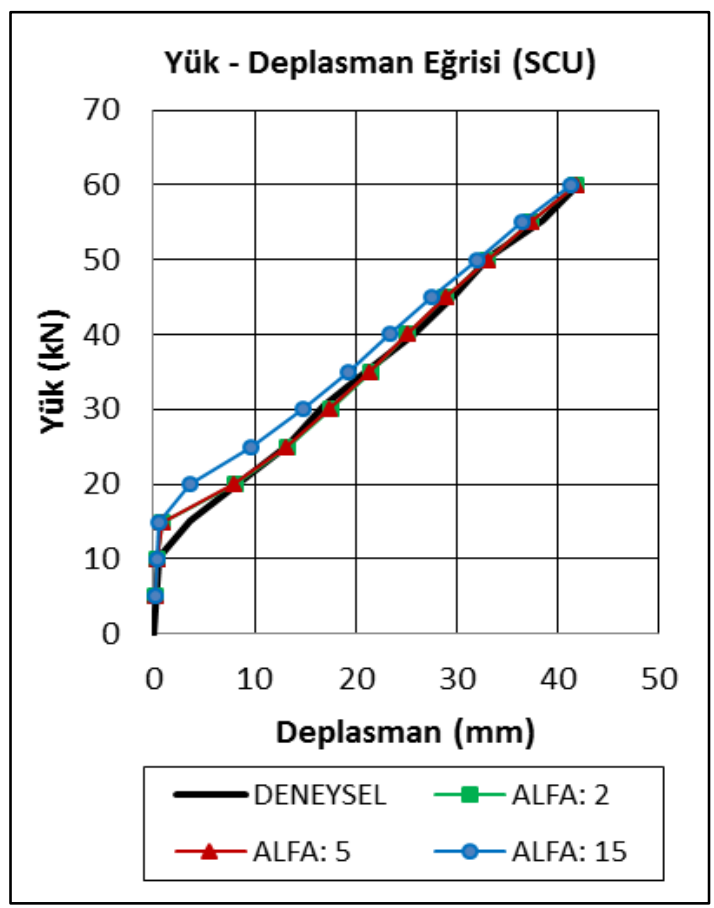

(1) 
Beton basınç dayanımları sırasıyla 42 ve $40,2 \mathrm{MPa}$ dir. Kopma gerilmeleri bazalt ve karbon lifli polimer için sırasıyla $1350 \mathrm{MPa}$ ve $1375 \mathrm{MPa}$ ' dır. Aynı kesit ölçülerine sahip olan iki kiriş arasındaki en belirgin fark donatıların elastisite modülü olup CBOO kirişi için $50 \mathrm{GPa}$ ve CCOO kirişi için 137 GPa dır. Şekil 7(a) ve 7(b) grafiklerindekine benzer şekilde burada da $\alpha_{t s}$ parametresinin, donat elastisite modülü $\left(E_{f}\right)$ ile önemli ölçüde ilişkili olduğu, $E_{f}$ arttıkça $\alpha_{t s}$ değerinin düştüğü anlaşılmaktadır. Benzer durum Şekil 7(e) ile 7(f) grafiklerinde de görülmektedir.

Şekil 7(c) ve 7(e) grafiklerinde CBOO ve CBOU kirişlerine ait yük-deplasman ilişkileri görülmektedir. Her iki kirişin donatıları bazalt lifli polimer donatı olup donatı çapları, elastisite modülleri, donatı oranları ve $\rho_{f} / \rho_{f b}$ oranları aynıdır. $\mathrm{Bu}$ kirişlerin beton basınç dayanımları sırasıyla 42 ve $43 \mathrm{MPa}$ dır. Bu kirişler arasındaki tek fark donatıların kopma gerilmeleri olup $\mathrm{CBOO}$ ve CBOU kirişleri için sırasıyla 1350 ve $1250 \mathrm{MPa}$ dır. Bu kirişler için $\alpha_{t s}$ değerleri sırasıyla 16 ve 17 olarak elde edilmiştir. Bu karşılaştırmada FRP donatıların kopma gerilmesinin çekme rijitleşmesi parametresi üzerindeki etkisinin oldukça sınırlı kaldığı görülmektedir.

Şekil 7(a) ve 7(c) grafiklerinde CBUU ve CBOO kirişlerine ait yük-deplasman ilişkileri görülmektedir. Her iki kirişin donatıları bazalt lifli polimer donatı olup elastisite modülleri aynıdır. Bu kirişlerin beton basınç dayanımları sırasıyla 43 ve $42 \mathrm{MPa}$ dir. Donatı kopma gerilmeleri sirasiyla 1250 ve $1350 \mathrm{MPa}$ olup kopma gerilmesinin $\alpha_{t s}$ parametresine etkisinin sınırlı olduğu göz önünde bulundurulunca, bu kirişler arasındaki en belirgin farkın donatı oranları olduğu anlaşılmaktadır. Açıklıkta çekme donatısı oranı $\left(\rho_{f}\right)$, CBUU kirişi için \%0,24 ve CBOO kirişi için \%0,63 olup $\rho_{f} / \rho_{f b}$ oranları ise sırasıyla 0,83 ve 2,52 'dir. Bu kirişler için $\alpha_{t s}$ değerleri sırasıyla 25 ve 16 olarak elde edilmiştir. Burada çekme donatısı oranının çekme rijitleşmesi parametresini önemli ölçüde etkilediği görülmektedir. Kesitte çekme donatısı oranı arttıkça $\alpha_{t s}$ değeri azalmaktadır. Aynı etki Şekil 7(b) ve 7(d) grafiklerinde verilen CCUU ve CCOO kirişlerine ait yük-deplasman ilişkilerinde görülmektedir. Denge altı donatı oranına sahip olan CCUU kirişi için $\alpha_{t s}$ değeri 12 iken, denge üstü donatı oranıyla tasarlanmış olan CCOO kirişi için $\alpha_{t s}$ değeri 5 olarak elde edilmiştir.

Mesnet bölgesindeki çekme donatısı oranının çekme rijitleşmesi parametresine etkisini incelemek üzere Şekil 7(c) ile 7(e) grafikleri karşılaştırıldığında, bu etkinin oldukça sınırlı kaldığı görülmektedir. $\mathrm{CBOO}$ ve $\mathrm{CBOU}$ sürekli kirişleri ile SBO basit mesnetli kirişlerinin donatı çapları, açıklıkta çekme donatısı oranları, $\rho_{f} / \rho_{f b}$ oranları, donatı elastisite modülleri ve donatı kopma gerilmeleri tamamen aynıdır.

CBOO kirişinin mesnet bölgesinde çekme donatısı oranı 2,52 iken $\alpha_{t s}$ değeri 16'dır. Bu kirişin sadece mesnetteki donatı oranının 0,83 'e düşürülmesiyle elde edilen CBOU kirişi için $\alpha_{t s}$ değeri sınırlı bir miktar artarak 17 değerine çıkmıştır. Şekil 7'de yük-deplasman ilişkisi verilen basit mesnetli SBO kirişi için ise $\alpha_{t s}$ değeri 16 olarak elde edilmiştir. Burada mesnet bölgesindeki çekme donatısı oranının ve kirişlerin mesnetlenme durumunun çekme rijitleşmesi parametresine etkisinin oldukça sınırlı kaldığ1 görülmektedir.

\section{SONUÇLAR}

$\mathrm{Bu}$ çalışmada çekme rijitleşmesinin, FRP ve çelik donatılı betonarme kirişlerin yük-deplasman davranışı üzerindeki etkisini incelemek üzere, literatürde mevcut çeşitli deneysel çalışmalarda test edilmiş olan sürekli kiriș numuneleri, kiriș kesitlerinin moment-eğrilik ilişkisine dayalı sayısal bir yöntemle analiz edilmiştir. Farklı çekme rijitleşmesi parametresi $\left(\alpha_{t s}\right)$ değerleri esas alınarak yapılan analizlerden oldukça farklı yük-deplasman eğrileri elde edilirken, deneysel sonuçlara en yakın yük-deplasman davranışını sağlayan $\left(\alpha_{t s}\right)$ değerlerinin, donatı oranı ve donatı elastisite modülü gibi faktörlere bağlı olarak önemli oranda değişkenlik gösterdiği görülmüştür.

Kirişlerde yüksek elastisite modülüne sahip FRP donatısı kullanılması durumunda, deneysel sonuçlara en yakın yük-deplasman davranışını sağlayan çekme rijitleşmesi parametresinin $\left(\alpha_{t s}\right)$ 
düşük değerlerde kaldığı, düşük elastisite modülüne sahip FRP donatısı kullanılan kirişlerin analizinde ise $\left(\alpha_{t s}\right)$ parametresinin yüksek değerler aldığı görülmüştür. Aynı mekanik özelliklere sahip FRP donatıların kullanıldığ 1 farklı kirişlerin analizi sonucunda, donatı oranı arttıkça çekme rijitleşmesi parametresi $\left(\alpha_{t s}\right)$ değerinin önemli ölçüde azaldığ 1 , sürekli kirişlerin mesnet bölgesindeki donatı oranının, $\left(\alpha_{t s}\right)$ seçimindeki etkisinin ise sınırlı kaldığı belirlenmiştir. Yukarıda yapılan değerlendirmeler sonucunda kirişlerin eğilme davranışını önemli ölçüde etkileyen çekme rijitleşmesi parametresinin $\left(\alpha_{t s}\right)$, büyük ölçüde kesitte kullanılan donatı oranı ve donatı elastisite modülüne bağlı olduğu anlaşılmaktadır.

\section{TEȘEKKÜR}

$\mathrm{Bu}$ çalışma Çukurova Üniversitesi Bilimsel Araştırma Projeleri Birimi tarafından desteklenmiştir (Proje No: FDK-2015-4924).

\section{KAYNAKLAR}

1. Stramandinolia R.S.B., Rovere H.L.L., 2008. An Efficient Tension-Stiffening Model for Nonlinear Analysis of Reinforced Concrete Members, Engineering Structures, 30: 20692080.

2. Allam S.M., Shoukry M.S., Rashad G.E., Hassan A.S., 2013. Evaluation of Tension Stiffening Effect on the Crack Width Calculation of Flexural RC Members, Alexandria Engineering Journal, 52: 163-173.

3. $\mathrm{Wu}$ H.Q., Gilbert R.I., 2009. Modeling ShortTerm Tension Stiffening in Reinforced Concrete Prisms Using a Continuum-Based Finite Element Model, Engineering Structures, 31: 2380-2391.

4. Yankelevsky D.Z., Jabareen M., Abutbul A.D., 2008. One-Dimensional Analysis of Tension Stiffening in Reinforced Concrete with Discrete Cracks, Engineering Structures, 30: 206-217.
5. Dundar C., Tanrikulu A.K., Frosch R.J., 2015. Prediction of Load-Deflection Behavior of Multi-Span FRP and Steel Reinforced Concrete Beams, Composite Structures, 132: 680-693.

6. ACI Committee 440. Guide For The Design and Construction of Structural Concrete Reinforced With FRP Bars. ACI440.1R-06, American Concrete Institute, Farmington Hills, MI; 2006. P. 44.

7. El-Nemr A, Ahmed EA, Benmokrane B. Flexural Behavior And Serviceability of Normal and High-Strength Concrete Beams Reinforced with Glass Fiber Reinforced Polymer Bars. ACI Struct J 2013; 110 (6): 1077-88.

8. Comité Euro-International du Béton (CEB). Manual on Cracking and Deformation, Bulletin D'information, No. 158-E; 1985.

9. Bischoff PH. Reevaluation for Deflection Prediction for Concrete Beams Reinforced with Steel and Fiber Reinforced Polymer Bars. J Struct Eng 2005;131(5):752-67.

10. ISIS Canada. Reinforcing Concrete Structures with Fiber Reinforced Polymers, Design Manual No. 3, ISIS Canada, Winnipeg, Manitoba; 2001.

11. Comité Euro-International du Béton(CEB). CEB-FIB Model for Concrete Structures, Bulletin 213/214; 1990.

12. Mahroug M.E.M., Ashour A.F., Lam D., 2014. Tests of Continuous Concrete Slabs Reinforced with Carbon Fibre Reinforced Polymer Bars, Composites : Part B, 66: 348-357.

13. Mahroug M.E.M., Ashour A.F., Lam D., 2014. Experimental Response and Code Modelling of Continuous Concrete Slabs Reinforced With BFRP Bars, Composite Structures, 107: 664674. 
